\title{
PARENTAL INCOME AND CHILD HEALTH IN GERMANY
}

Steffen Reinhold und Hendrik Jürges

175-2009

๑) mea-Mannheim Research Institute for the Economics of Aging

\begin{tabular}{l|l|l|l|l|l|l|l|l|l|l|}
\hline & & & & & & & \\
\hline
\end{tabular}

L13, 17_D-68131 Mannheim_Phone +49 621 181-2773/1862_Fax +49 621 181-1863_www.mea.uni-mannheim.de 


\title{
Parental Income and Child Health in Germany
}

\author{
Steffen Reinhold* Hendrik Jürges ${ }^{\dagger}$
}

March 25, 2009

\begin{abstract}
We use newly available data from Germany to study the relationship between parental income and child health. We find a strong gradient between parental income and subjective child health as has been documented earlier in the US, Canada and the UK. The relationship in Germany is about as strong in the US and stronger than in the UK. However, in contrast to US results, we do not find that the disadvantages associated with low parental income accumulate as the child ages, nor that children from low socioeconomic background are more likely to suffer from 'objectively measured' health problems - except for obesity. There is some evidence, however, that high income children are better able to cope with the adverse consequences of chronic conditions. Finally, we do not find that child health (except for low birth weight) plays a major role in the explanation of educational attainment once parental income and education are controlled for.
\end{abstract}

Keywords: Parental Income, Child Health, Educational Attainment JEL-Codes: I12, J13

*reinhold@mea.uni-mannheim.de; MEA, University of Mannheim; L13, 17; 68131 Mannheim, Germany; Phone: +49 (621) 181-3505.

†juerges@mea.uni-mannheim.de; MEA, University of Mannheim; L13, 17; 68131 Mannheim, Germany; Phone: +49 (621) 181-3519. 


\section{Introduction}

Persons with high socioeconomic status (SES) are in better health and they live longer. Although the empirical finding of an SES-health gradient is very robust, there is an ongoing debate about the underlying reasons for this relationship. The positive correlation could arise because (i) better health leads to better education and income (Currie and Madrian 1999), (ii) education, income or occupational status cause better health outcomes (Grossman 1972), or (iii) there are third factors as for instance genetic endowments or time preference rates affecting both socioeconomic status and health (Fuchs 1982).

In order to uncover the "origins of the gradient", Case, Lubotsky and Paxson (2002), henceforth denoted as CLP, investigate whether this association between socioeconomic status and health can also be found among children. They argue that - since children in industrialized countries do not work in the labor market - there is less of a problem of reverse causality running from poor health to decreased earnings. Using US cross-sectional data they find a strong positive relationship between parental income and children's subjective health. This relationship strengthens as children grow older, which points to an accumulation of health disadvantages for children of low-income parents. Moreover, low-income children are more likely to have chronic health conditions, and the impact of chronic conditions on parent-assessed general health is worse than for children of high-income parents.

The CLP study has been highly influential and it has been replicated with Canadian (Currie and Stabile 2003) and British data (Currie, Shields and Price 2007). Currie and Stabile use panel data and find that, like in the US, the gradient between parental income and children's health steepens as children grow older. However, they do not find that highSES children suffer less from the long-term consequences of chronic conditions. ${ }^{1}$ Rather they find that low-SES children are more likely to attract chronic conditions. For the UK, Currie et al. (2007), henceforth denoted as CSW, find a smaller gradient between parental income and subjective health measures than has been found in the US and Canada. In contrast to the US and Canada the gradient does not steepen with the children's age. In addition to

\footnotetext{
${ }^{1}$ CLP only use cross-sectional data and do not address this question.
} 
subjective health, CSW also use information from biomarkers such as blood haemoglobin and ferritin levels. For these objective measures they find no income gradient. They conclude that parental income is only a minor factor for child health in England. Rather it is parents' behavior which is important. In an earlier study, Currie and Hyson (1999) have found that the adverse effects of low birth weight on children's long-term prospects do not vary much by socioeconomic status. These two studies point to an important difference between the UK on one side and the US and Canada on the other side. Institutional factors, such as the NHS, might weaken the strong association between parental income and children's health in the UK. Given these contrasting findings for the UK, US, and Canada it is interesting to look at Germany as another industrialized country with similar levels of household income.

If the "origins of the gradient" can be traced back to childhood conditions, there may be another potential disadvantage for children from low SES households. In addition to being sicker, they may face more challenges in school and accumulate less human capital than their peers. If this is the case, low SES children enter adulthood with lower levels of human capital, both in health and formal education. Childhood health may then play an important role for the intergenerational transmission of socioeconomic status. Case, Fertig and Paxson (2005) find that even after conditioning on parental background, UK children in poor health have lower educational attainment and worse health outcomes at the beginning of adulthood. For Germany, Salm and Schunk (2008) have found that a large part of the variation in cognitive abilities at the age of school entry are explained by health problems which are differing by socioeconomic status.

The aim of our study is to add to the emerging literature on socio-economic status and child health by exploiting newly available data from Germany. We study the "origins of the gradient" using data from the German Interview and Examination Survey for Children and Adolescents (KIGGS). First, we replicate the analysis in CLP, examining the relationship between parental background and children's health in Germany. Drawing on their approach, we decompose this correlation into a "prevalence effect" and a "severity effect". We analyse whether low SES children have more chronic conditions and whether they are less able to 
cope with chronic conditions.

Second, in addition to the subjective health assessments by the parents, we also have information on objective health measurements such as blood pressure, haemoglobin and ferritin levels. CSW have found a gradient for the subjective measure but not for the objective measures of health, and we investigate whether this empirical finding translates to Germany as well.

Third, low birth weight is another objective measure of children's health and we investigate whether there are long-term effects of low birth weight on children's health, and whether these effects differ by socioeconomic status. Low birth weight may play an important role in the intergenerational transmission of human capital, especially if there is an intergenerational transmission of low birth weight (Currie and Moretti 2007). Similarly, Behrmann and Rosenzweig (2004) find that genetics play the dominant role in the intergenerational correlation of birthweight.

In our study, we have cross-sectional information on only one child per household. Recently, the use of cross-sectional data has been criticized for inferring the causal effect of low birth weight on children's outcome because low birth weight could be correlated with genetic endowments and other behavioral risk factors such as drinking or smoking. A woman who takes these risks during pregnancy may also invest less in children during their upbringing. Almond, Chay, and Lee (2005) use twin fixed-effect estimators and find that the effect of low birth weight on short-run outcomes such as health at birth, mortality, and hospital costs are lower than the OLS estimates would suggest. Similarly, Black et al. (2007) show that if twin fixed-effects are accounted for, low birth weight has only small short-run effects on health outcomes (5 minute APGAR scores and one year mortality). ${ }^{2}$ However, they find long-run effects on adult height, high school completion rates or earnings that are comparable to OLS estimates. Thus, for long-run outcomes the bias of OLS in cross-sections may be small giving some confidence in our cross-sectional results.

Fourth, we study whether socioeconomic status interacts with health problems in the

\footnotetext{
${ }^{2}$ The APGAR test is done one and five minutes after birth to assess whether the newborn needs medical attention. It consists of five compontents Appearance, Pulse, Grimace, Activity, and Respiration.
} 
determination of educational attainment, for example because high SES parents are able to better compensate their children's health problems, and thus educational attainment is less constrained by health problems. We use information on grade retention and attending the highest (academic) track in the German three-tier school system as measures of educational attainment.

When interpreting the correlation between parental income and children's outcomes as a causal effect some caution is required. A correlation could also arise from reverse causality or third factor explanations. As CLP note, however, poor child health does not depress family earnings in industrialized countries because children do not usually contribute to family income. ${ }^{3}$ However, they cannot exclude the possibility of other third factor explanations. In robustness checks we aim at assessing whether the gradient between parental income and child health is much affected by including additional controls for parents' health behavior and insurance status. If the coefficient on parental income is robust to a wide range of such additional background variables we would cautiously interpret our findings as causal. ${ }^{4}$

\section{Data and Descriptive Statistics}

We use data from the German Interview and Examination Survey for Children and Adolescents (KIGGS) public use file. KIGGS is a nationally representative sample of of 17,641 children aged 0-17 residing in Germany, conducted over the years 2003-2006. Data were collected in self-completion questionnaires of parents and children older than 10, medical face-to-face interviews with parents, and in medical examinations undertaken by trained medical staff. ${ }^{5}$

Although part of the survey was also administered to children older than 10, we use

\footnotetext{
${ }^{3}$ However, it could be the case that parents restrict their labor supply as a reaction to their children's health.

${ }^{4}$ Unfortunately, we do not have suitable instruments for parents' education or income. There is now a growing literature using natural experiments arising from changes in educational policy as instruments for parental education on children's outcomes (Currie and Moretti 2003, Lindeboom et al. 2006, McCrary and Royer 2006, Black et al. 2005). The evidence of this literature is inconclusive so far.

${ }^{5}$ For further details see the KIGGS website http://www.kiggs.de/service/english/index.html
} 
in our study only information from the parent questionnaires and medical interviews. To avoid problems with systematic differences in answering behavior between parents we have dummies for answers from mothers, fathers, joint answers or answers by third persons (for example for children living in institutions).

Similar to CLP we use subjective child health assessed by the parents (or other persons) as our main outcome variable for health. This variable is derived from the self-completion questionnaire and originally coded in five categories: 1='very good', 2='good', 3='fair', $4=$ 'bad', $5=$ 'very bad'. However, less than one percent of the respondent rated their child's health as 'bad' or 'very bad'. We have thus collapsed the 'fair', 'bad' and 'very bad' into a single category. Depending on the analysis, we either use the recoded three-category variable as dependent variable in ordered response models or we use a binary indicator for "very good' and 'good' versus 'fair' to 'very bad' subjective health. We also derive information on children's birth weight and whether the child wears glasses from the self-completion questionnaire.

In addition to self-assessments, we look at more detailed self-reported health problems. Parents were asked whether their child had ever been diagnosed with hayfever, neurodermatitis, chronic obstructive bronchitis, lung infection, asthma, heart problems, diabetes, migraines, scoliosis, thyroid problems, cramps or epileptic fits. Finally, we use blood ferritin and haemoglobin levels, measured height and weight and blood pressure - all obtained in the course of medical examinations - as objectively measured indicators of health.

Current monthly parental income is reported in 13 bands, ranging from below 500 Euro to above 5000 Euro. We use the interval midpoints as our measure of parental income, and 250 Euro and 7,500 Euro for the lowest and highest band, respectively. We further use information on parental schooling (reflecting the different tracks in Germany's secondary schools), college or university degrees, unemployment, and migrant status. In our study the term parents always refers to 'social' parents and not necessarily biological parents. Thus, if a child lives with her divorced mother and her new partner, then this male person would be the father figure. Information on parental background such as education would refer to this 
new partner. If there is no father figure present, the dummy variables for father's education all take the value of zero. To account for family structure, we use a full set of dummies for the most common types of living arrangements such as living with both biological parents, living with a single mother or father, living with biological mother and new partner and so on. Furthermore, we use the information on the number of siblings to control for household composition because of a possible correlation of family size and investments in human capital (Becker and Lewis 1976, Black, Devereux and Salvanes 2005).

In additional analyses, we investigate whether private insurance status may explain differences in health outcomes between high and low income families. In Germany, there is universal health insurance coverage. However, self-employed, civil servants and employees with income above a certain threshold can opt out of the public system and get private insurance. By including information on private health insurance status we can assess whether better health outcomes of high income children are due to access to the private insurance market. Furthermore, we construct measures for parental health behavior such as parental smoking, drinking and self-reported health and weight and include them in our regressions.

— about here Table 1 -

Table 1 contains summary statistics for the sample used in our study. Overall, the children in our sample appear to be very healthy. 40 percent of the parents described the health of their child as very good and another 54 percent decribed the health of their child as good. Only 6.4 percent said their child is in fair or worse health. 6.2 percent of the children had low birth weight $(<2,500 \mathrm{~g})$. Among the (chronic) health problems, bronchitis (12.5 percent) and hayfever (9.8 percent) were the most common. Only 0.1 percent of the children had been diagnosed with diabetes. 18.8 percent of the children wore glasses. 6.1 percent of the children were classfied as obese (defined as being above the 97th percentile of the German reference population) and 0.8 percent suffered from high blood pressure (diastolic bp $>90$ mmHg). Finally, low haemoglobin $(<12 g / d l)$ and ferritin $(<17 \mu g / d l)$ levels were found for 15.4 and 12.8 percent of the children, respectively. 
We measure the socio-economic background by four main variables. Income, education, employment status, and immigrant status. Median net monthly family income was 2,375 Euro. Parental education is measured by the school leaving certificate (basic, middle, or grammar school) and college degree. Education levels of mothers and fathers are quite similar: 30.7 percent of fathers and 29.3 percent of mothers had at least finished grammar school. Variance in education levels is somewhat greater for fathers, with larger proportions having finished only basic school or college. Note that in Table 1, we do not show two residual categories ('no leaving certificate' and 'no information available'), which account for about 10 percent of the fathers and mothers. Children are defined as having a migration background (a) if they are not born in Germany and have at least one parent not born in Germany, or (b) if both parents are not born in Germany. According to this definition, about 15 percent of the children in the sample have a migration background.

\section{Empirical Models and Results}

\subsection{Parental Income and Self-Assessed Health}

The first step in our analysis is to estimate ordered probit models in order to gauge the association between subjective health and log parental income using different sets of control variables. These estimates are directly comparable to the results reported in CLP and CSW. One might be concerned about comparability between the "US"-version of the selfrated health question used in Case et al. - which has five categories ranging from "excellent" to "poor" - and the "European" version used in CSW and also in our study - ranging from "very good" to "very bad". However, recent evidence suggests that although health levels are not directly comparable across the two response formats, both versions are in fact different categorizations of the same latent continuous variable (Jürges, Avendano and Mackenbach 2008). In particular, both scales were found to have the same properties with respect to demographics and health indicators. Thus, data from surveys using different self-rated health versions could still be used to compare associations of covariates with general health. This 
requires the use of appropriate statistical models (such as ordered probit models) that interpret self-rated health as different categorisations of an underlying (latent) continuous health variable.

— about here Figure 1 -

We present first evidence for the relationship between parental income and self-rated child health, by age group, in Figure 1. Higher values of subjective health mean worse health. Figure 1 clearly shows that children in households with a high net income are healthier than children in low income households. Consistent with many earlier findings, the relationship can be described as a gradient, i.e. there appears to be no threshold value at which income becomes unimportant for health, and the positive association between income and health can be found also among the very high income households. In US data, CLP find that the slope of the family income-health gradient increases in absolute size as children become older. They interpret this result as support for the notion that the socioeconomic disadvantages in health accumulate over time. For this reason one should find a bigger effect of parental income in older children. Our preliminary graphical analysis does not confirm this finding. We find that older children are on average less healthy than younger children, much more so than in comparable US and UK data. More importantly, the gradients for different age groups are essentially parallels. This holds in particular in the middle of the income distribution where we have many cases.

To account for the ordinal nature of our dependent variable and to control for covariates, we show ordered probit regression results for the relationship between parental income and subjective health in Table 2. In the upper panel we present a baseline specification including as covariates a full set of age dummies (in years), sex of child, log of household size, parity of birth, a dummy for being a twin age of parents, dummies for family background and respondent, migrant status, dummies for East Germany and rural areas. In the lower panel we present results from a specification that includes additional control variables for parental education and unemployment. Again, we do this to compare our results with those of CLP 
(Table 2), who find that including additional controls for parental education and employment status reduces the coefficients on parental income by around a third.

- about here Table 2 -

In accordance with expectations, we find a highly significant correlation between parental income and children's subjective health. In our baseline specification, a one log point increase in parental income is associated with a 0.262 improvement in latent health, which corresponds to a 2.9 percentage point decrease in the probability of reporting fair or worse health. Compared to the overall average of 6.4 percent of parents who report fair or worse health, this is a sizeable effect. Thus, we find that also in Germany, parents with higher income have children who are in better health. This holds true in all age groups.

Note that some of our point estimates are actually strikingly similar to those reported in CLP. For instance, in the 13-17 age range, a one log point increase in parental income is associated with a 0.313 improvement in latent health. The corresponding figure for the US reported in CLP is 0.323. However, in contrast to CLP we do not find that the effect of parental income increases uniformly with child age. The gradient is steeper than in the US already for children aged 0 to 3 (-0.240 versus -0.183) and remains fairly stable until age 12. Part of the US increase in the gradient with child age can also be explained (at least statistically) by smaller initial health inequalities in the US. Similar to our results, CSW find no age-related increase in the gradient in UK data.

Another difference between our results and those found for the US is that the coefficient on parental income is less affected by the inclusion of control variables for parental education and unemployment. Thus, the association of self-reported health and parental income is not just due to the fact that parents with higher income are better educated. Rather, parental income has a strong independent effect even when holding parental education constant. Moreover, the coefficients on parental education are not always significant. The reference category are mothers and fathers with a basic school leaving certificate. A positive effect of parental education on child health is found if the reported coefficients are negative and 
increasing in absolute size from top to bottom. This pattern is found particularly for mother's education among 4 to 8 year olds and father's education among the 13 to 17 year olds. Note finally that controlling for parental education and unemployment brings us further away from the US result of a gradient that becomes stronger as children age. Rather, we find a U-shaped pattern with largest income-related inequalites in health for infants and teenagers.

\subsection{Prevalence and Severity Effects of Income}

In this subsection, we use information on the presence of doctor-diagnosed (chronic) health problems to decompose the effect of parental income into two components (Case el al. 2002). First, children from poorer families may suffer more often from chronic conditions (prevalence effect). Second, children from poorer families may be less able to cope with the consequences of chronic (or acute) conditions (severity effect). To assess the importance of the prevalence effect we estimate the following linear probability model:

$$
C=\alpha_{0}+\alpha_{1}(\ln y-\overline{\ln y})+X \delta^{C}+\varepsilon^{C}
$$

where $C$ is a dummy for one of the conditions such as hay fever or asthma, $y$ is family income, and $X$ are additional control variables. $\alpha_{1}$ is the coefficient on family income. Negative values of $\alpha_{1}$ mean that children from richer households are less likely to have the condition. This also informs about how much of the disparity in health is due to the prevalence effect. Equations similar to equation (1) are also estimated when the relationships between parental income and objective health measures such as blood pressure, and haemoglobin and ferritin levels are evaluated.

The quantitative importance of the severity effect is assessed in a separate equation. We estimate the following linear probability model separately for each health problem:

$$
H=\beta_{0}+\beta_{1}(\ln y-\overline{\ln y})+\beta_{2} C+\beta_{3}(\ln y-\overline{\ln y}) \times C+X \delta^{H}+\varepsilon^{H}
$$


where $H$ takes the value of 1 if the child is in parent-reported fair or worse health. $\beta_{1}$ reflects the effect of log familiy income on the probability of reporting fair or worse health, $\beta_{2}$ captures the 'main' effect of a chronic health problem on subjective health and answers the question of how much each individual condition affects general health. The interaction between the logarithm of parental income and the chronic condition reflects the severity effect of income, i.e. the effect of income on how much a chronic health problem affects general health. For instance, if children from richer families are better able to cope with the consequences of chronic conditions, the coefficient $\beta_{3}$ should be negative.

Results for the prevalence and severity effect are shown in Table 3. The coefficient $\alpha_{1}$ in equation 1 captures the prevalence effect. In contrast to CLP's findings for the US but in accordance with CSW's findings for the UK, we do not find that parental income has a significant effect on the prevalence of doctor-diagnosed conditions - the only exception being hay fever and neurodermatitis, for which we find a positive gradient. Note that this finding is at odds with the consistent income gradient found for subjective health. We will return to this point later when we analyse 'objective' measures of health in more detail.

— about here Table 3 -

Table 3 also shows estimation results for equation (2). First, we find a strong protective effect of income on children's subjective health, which reiterates our results from Table 2. Second, each of the chronic conditions has a highly significant impact on subjective health $\left(\beta_{2}\right)$. In particular, parents of children suffering from diabetes, asthma, and epilepsy (with effects of 11 to 30 percentage points) are more likely to report fair or worse general child health. Third, the coefficient of the interaction of chronic conditions and parental income $\left(\beta_{3}\right)$, captures the severity effect. It is significantly negative for hayfever, bronchitis, asthma, and scoliosis and negative but insignificant for all other conditions. This means that children of richer parents having one of these four conditions are less likely to be in fair or worse general health than children of poorer parents with the same conditions. Possibly the symptoms of the hayfever, bronchitis, asthma, and scoliosis are less severe for children from richer parents, 
or richer parents are better able to manage these conditions. To summarize the results of this part of our analysis, parental income appears to play a role for health in Germany not because children of richer parents are less likely to suffer from any health problems measured in our data. A partial role of parent income is due to the fact that richer parents are better able to protect their children when having a chronic condition.

\subsection{Long-term Impact of Low Birth Weight on Subjective Health}

In this subsection we investigate whether low birth weight $(<2500 \mathrm{~g})$ has a long lasting impact on self-reported health, and whether possible disadvantages of low birth weight dissipate over time or are affected by parental income. To this end, we include a dummy variable for low birth weight as an explanatory variable in our initial ordered probit specification. We add interactions between low birth weight and age to assess whether the impact of low birth weight dissipates over time, and interactions between family income and low birth weight to assess whether parents with higher incomes are better able to compensate for possible problems due to low birth weight. ${ }^{6}$ Specifications that include low birth weight have the advantage that we can exclude the possibility of reverse causality between parental income and child health when parents reduce their labor supply as a response to their children's bad health.

— about here Table 4 -

In the first column of Table 4, we show a basic specification similar to Table 2, which now excludes observations with missing information on birth weight. In column 2, we include a dummy variable indicating low birth weight. Children with low birth weight are in worse subjective health than children with normal birth weight. Including this additional variable does not much affect the coefficients on parental income. In column 3 we include an interaction term of low birth weight with age. If the disadvantages of low birth weight

\footnotetext{
${ }^{6}$ We are aware that the interpretation of interaction effects in non-linear regression models is more complicated than in OLS (Ai and Norton 2003). We have checked our results with linear models and found them to be similar in magnitude, sign and statistical significance.
} 
dissipate over time then we would expect a negative coefficient. This is indeed what we find. The point estimate indicates a reduction of the low birth weight effect of about a third (from 0.137 at birth to 0.086 at age 17$)$. But the interaction effect is imprecisely estimated and hence statistically insignificant.

We are also interested whether parents with higher income are better able to compensate for the potential disadvantages associated with low birth weight. In column 4, we add an interaction term between low birth weight and parental income. We find a positive, though insignificant, coefficient on this interaction term indicating that higher income parents are not better able to compensate for the adverse affects of low birth weight. Again, note that in all specifications so far, the coefficient on parental income itself is not much affected, which indicates that the positive effect of parental income on health cannot be explained by parental income being related to problematic birth weight. Even if there is an association between current income and birth weight, there is an additional effect of parental income which cannot be explained by low income parents having more problematic births. This conclusion is also robust to including more interactions as in columns 5 and 6 where the coefficient on parental income does not change much in comparison to the basic specification.

As a robustness test, we check in Table 5 whether different operationalizations of birth weight make a difference for our results. In the first column we repeat the specification with a dummy for low birth weight. When we use alternative variables such as birth weight in $\mathrm{kg}$, fetal growth (birth weight/gestational period), or log birth weight, we generally find more significant results, and using log birth weight seems to be the best empirical specification. However, including interaction effects of birth weight measures with log income (not shown) yields insignificant results throughout. Thus, we conclude that low birth weight has longterm adverse effects on subjective health. These disadvantages dissipate somewhat with age, but high income parents are not better able to protect their children from these adverse effects. Furthermore, we also find that the protective effect of current parental income on children's health cannot be explained by a correlation between their permanent income and problematic birth weight because including low birth weight does not much affect the point 
estimates of the coefficients on parental income.

— about here Table 5 -

\subsection{The Gradient for Objective Measures of Health}

In Table 6 we report results for the relationship between objectively measured health indicators and parental income. CSW found no relationship between parental income and objective measures of health in their UK data. A similar picture emerges for Germany for high blood pressure, low haemoglobin, and low ferritin blood content. However, we do find a strong and significant relationship between parental income and obesity, which was not found in the UK. This holds despite the fact that we also find a strong independent parental (especially mother's) education effect on childhood obesity. We have also computed summary measures for objective health, combining information of doctor-diagnosed health problems and medical tests outcomes. In column (5) of Table 6, we show the relationship between parental income and a simple count of conditions. Here we actually find a positive effect of income (maybe due to the 'hayfever-effect'). In column (6) we use a more refined summary measure of objective conditions ('latent health'). The latent health index is computed as the linear prediction of an ordered probit regression of subjective health on condition dummies - see e.g. Jürges (2007). The idea of this index is to weight each condition by its effect on general health (also known as disability weight). However, we do not find significant effects of income or education when using this refined measure of overall health.

- about here Table 6 -

\subsection{The Roles of Private Insurance and Parents' Health Behavior}

We continue our investigation into the determinants of subjective health by looking at several explanations for the correlation between parental income and child health. First, we include parental insurance status in our regressions. In Germany, there is almost universal, mandatory health care coverage. However, there are some exceptions for public servants, 
self-employed and persons with high monthly income (in 2009 the cutoff was 4,050 Euro per month). Members of these groups can opt out of the public system and get private insurance for themselves and their families. Around $10 \%$ of the population are insured privately. Opting out of the statutory health insurance system is attractive for two reasons: average fees are lower and health care services are usually more comprehensive. Since having a private health insurances is highly correlated with income, the income-health gradient could be partly explained by the fact that children of high income parents have access to better or more comprehensive health care.

We present the results for private insurance status in Table 7, column (1). Including private insurance status does not affect the coefficient on parental income much. The coefficient for private insurance is positive but statistically insignificant. This would mean that children with private insurance have worse health outcomes. This finding does not change much when we include an additional interaction between private insurance status and logged family income in column (2).

\section{— about here Table 7 -}

As another explanation for the parental income-child health gradient, we investigate whether including information on parental health behavior such as smoking, drinking, and weight problems reduce the explanatory power of parental income. If high income parents have better health behavior, the relationship between parental income and children's health could be explained by differences in parental health behavior.

Results are presented in column (3) of Table 7. We have constructed indicator variables for whether the parents are current smokers and whether they smoke inside the house. Furthermore, we use dummy variables for smoking and drinking during pregnancy. Based on self-reported weight and height we use indicators for parental overweight $(B M I>25)$. We find that smoking fathers and overweight mothers are significant dangers for child health. However, the coefficient on parental income is not much affected by accounting for bad health behavior on the part of the parents. Thus, we do not find that the strong relationship 
between parental income and children's health is mainly driven by more healthy behavior of high income parents.

Of course, our two additional analyses do not exclude the possibility that there are still other unobserved factors driving or mediating the correlation between parental income and subjective child health, nor do they exclude the possibility that because of genetic ties both 'ability' and health are positively correlated across generations. Since the sample contains only few children living with non-biological parents only, we cannot further investigate the issue of genetic versus environmental determinants of childhood health.

\section{Child Health and Educational Attainment}

So far, we have investigated the impact of parental income on children's health. We now turn to the question of the impact of poor childhood health on educational outcomes. This could be an important pathway in understanding the intergenerational transmission of human capital. We have seen that parental income is an important correlate of children's subjective health. If sick children have less academic success, this could be one important pathway by which low socioeconomic status is transmitted from one generation to the next. One important further question is whether richer parents can better buffer the effects of ill health on education.

\subsection{Chronic Conditions and Educational Attainment}

We begin by estimating the effect of chronic conditions on educational attainment using the following linear probability model:

$$
E=\gamma_{0}+\gamma_{1}(\ln y-\overline{\ln y})+\gamma_{2} C+\gamma_{3}(\ln y-\overline{\ln y}) \times C+X \delta^{E}
$$

where $E$ is an indicator variable for attending the academic track (grammar school) in the three-tier German secondary school system. Estimation results for equation (3) are shown 
in Table 8. Estimation samples are now smaller because we restrict the analysis to children aged 13 or older (i.e. children who are in secondary school). In each regression, a dummy for attending the academic track is the outcome of interest. Separate models are estimated for each chronic condition. The coefficient on parental income, $\gamma_{1}$, gives insight into the effect of parental income. We expect a positive coefficient, i.e. children of high income parents are more likely to attend the academic track. The coefficient on each of the chronic conditions, $\gamma_{2}$, shows whether attending the academic track is affected by the chronic condition. If this is the case, we expect a negative coefficient. In addition, we also interact each of the chronic conditions with parental income. This latter coefficient, $\gamma_{3}$, allows conclusions about a severity effect with respect to academic success. If high income parents are better able to cushion the adverse effects of chronic conditions we expect this coefficient to be positive.

\section{— about here Table 8}

In line with earlier studies (Schneider 2008), we find very strong evidence for the relationship between parental income and the likelihood of attending the academic track. The coefficient on parental income, $\gamma_{1}$, is large in size and statistically significant in all specifications. For chronic conditions, a different picture emerges. Some of the coefficients on chronic conditions are statistically significant, but the signs are not all negative. The interaction between parental income and chronic conditions is not significant, either. While parental income plays a role for educational attainment, this is not because high income parents are able to better deal with chronic health problems of their children. From our previous results

we also know that parental income does not seem to play a role for the prevalence of chronic conditions. Thus, the main effect of parental income on children's educational attainment must have other causal pathways than via children's health.

\subsection{Low Birth Weight and Educational Attainment}

We have already found that low birth weight has a long-term impact on the subjective health of children. Similar to our specification in the preceding subsection, we now estimate 
equations where low birth is substituted for chronic conditions in equation 3. We thus assess whether low birth weight has a long-run impact on educational attainment and whether richer parents are better able to compensate for the problems associated with low birth weight.

Our results are shown in Table 9 . In column 1 we simply reproduce our earlier empirical results without including indicators for low birth weight. Again, we find a strong positive relationship between parental income and the probability that the child attends the academic track. Moreover, we find a very strong relationship between parental and children's education. Children of better educated parents have much higher chances of attending the academic track (Jürges and Schneider 2007).

— about here Table 9 -

In the second column, we add a dummy variable for low birth weight. Low birth weight has a strong influence on the probability of attending the academic track. Because we measure educational attainment at age 13 and older, this suggests that low birth weight has long-term effects on children's education. This is consistent with prior findings by Currie and Hyson (1999) for the UK. Currie and Hyson also found no variation in the effect of low birth weight by socioeconomic status. In other words, high income parents in the UK are not able to better cushion the adverse effects of low birth weight than poorer parents. When replicating this analysis in columns 3 and 4, we also find little evidence for Germany that there is variation in the effect of low birth weight on educational outcomes by socioeconomic status. Again, this indicates that high income parents are not better equipped to protect their children from the adverse effects of low birth weight.

We finally investigate whether our results for educational attainment are robust to using grade retention as an alternative outcome variable (see Table 10). When we use grade retention as our measure of educational attainment we still find that parental income has a big influence. Children of high income parents are less likely to repeat a class, and this effect is statistically significant. Low birth weight is a weak predictor for grade retention and 
statistically not significant. However, the point estimates are consistent with our previous estimates indicating that children with low birth weights have a harder time keeping up with their peers in school. Again, there is no variation in the impact of low birth weight by SES.

— about here Table 10 -

\section{Summary and Discussion}

In this paper, we have used newly available data from Germany to study the relationship between parental income and child health. In our empirical analysis we find a strong gradient between parental income and subjective child health as has been documented in the US (Case, Lubotsky and Paxson 2002), Canada (Currie and Stabile 2003) and to a somewhat lesser extent in the UK (Currie et al. 2007). The relationship in Germany is about as strong as in the US and stronger than in the UK. In contrast to the US and Canada, but consistent with UK findings, we do not find that the disadvantages associated with low parental income accumulate as the child ages. We also do not find that children from low socioeconomic background are more likely to suffer from chronic health problems - except for a somewhat elevated risk of obesity - or have worse medical measurements of health such as high blood pressure or low blood haemoglobin levels. There is some evidence, however, that high income children are better able to cope with the adverse consequences of chronic conditions, in particular hay fever, bronchitis, scoliosis, and asthma.

Consistent with the education literature, we find that parental income and the children's academic attainment are strongly positively related. This indicates that that low socioeconomic status is transmitted from one generation to the next. However, we do not find that child health plays a major role in this intergenerational transmission except perhaps for low birth weight. But even in the case of low birth weight the adverse effects do not vary systematically by socioeconomic status.

The fact that we find conflicting results for the effect of parental income on parent-

assessed subjective health on the one hand and most doctor diagnosed conditions and objec- 
tively measured health indicators, on the other hand, is disquieting. Self-reports of health are subject to considerable over-, under-, or misreporting, depending on the circumstances and dimensions at hand (Jürges 2007, Jürges 2008, Bago d'Uva, O'Donnell and van Doorslaer 2008). This becomes problematic if the reporting bias is correlated with important potential determinants of health such as income. Still, self-reports of health have their own distinct scientific value. For instance, it has been shown that they contain information on health status even after conditioning on objective measures of health (Idler and Benyamini 1997). Thus, results from 'objective' measures including biomarkers should be seen as complementary evidence rather than some higher order of evidence. However, the value of self-assessments alone as policy outcome measures is less clear. It would be hard to evaluate the benefits of a health care reform or massive income redistribution, say, that improves subjective health but leaves more objective measures of health unchanged. 


\section{References}

Ai, Chunrong and Edward C. Norton, "Interaction terms in logit and probit models," Economics Letters, 2003, 80 (1), 123-129.

Almond, Douglas, Kenneth Y. Chay, and David S. Lee, "The Costs of Low Birth Weight," Quarterly Journal of Economics, August 2005, 120 (3), 1031-1083.

Bago d'Uva, Theresa, Owen O'Donnell, and Eddy van Doorslaer, "Differential health reporting by education level and its impact on the measurement of health inequalities among older Europeans," International Journal of Epidemiology, 2008, 37 (6), 1375-1383.

Becker, Gary S. and H. Gregg Lewis, "On the Interaction between the Quantity and Quality of Children," Journal of Political Economy, 1976, 84, S143-S162.

Behrman, Jere R. and Mark R. Rosenzweig, "Returns to Birthweight," Review of Economics and Statistics, May 2004, 86 (2), 586-601.

Black, Sandra E., Paul J. Devereux, and Kjell G. Salvanes, "The More the Merrier? The Effect of Family Size and Birth Order on Children's Education," Quarterly Journal of Economics, May 2005, 120 (2), 669-700.

_ on Adult Outcomes," Quarterly Journal of Economics, February 2007, 122 (1), 409-439.

Case, Anne, Angela Fertig, and Christina Paxson, "The Lasting Impact of Childhood Health and Circumstances," Journal of Health Economics, 2005, 24, 365-389.

, Darren Lubotsky, and Christina Paxson, "Economic Status and Health in Childhood: The Origins of the Gradient," American Economic Review, December 2002, 92 (5), 1308-1334. 
Currie, Alison, Michael A. Shields, and Stephen Wheatley Price, "The Child Health/Family Income Gradient: Evidence from England," Journal of Health Economics, 2007, 26, 213-232.

Currie, Janet and Brigitte C. Madrian, "Health, Health Insurance, and the Labor Market," in O. Ashenfelter and D. Card, eds., Handbook of Labor Economics, Vol. 3, Amsterdam: Elsevier Science, 1999, pp. 3309-3414.

and Enrico Moretti, "Biology as Destiny? Short- and Long-Run Determinants of Intergenerational Transmission of Birth Weight," Journal of Labor Economics, 2007, 25 (2), 231-263.

and Mark Stabile, "Socioeconomic Status and Child Health: Why is the Relationship Stronger for Older Children," American Economic Review, 2003, 93, 1813-1823.

and Rosemary Hyson, "Is the Impact of Health Shocks Cushioned by Socioeconomic Status?," American Economic Review, Papers and Proceedings, May 1999, 89 (2), 245250.

Fuchs, Victor R., "Time Preference and Health: An Exploratory Study," in V.R. Fuchs, ed., Economic Aspects of Health, University of Chicago Press, 1982, pp. 93-120.

Grossman, Michael, "On the Concept of Health Capital and the Demand for Health," Journal of Political Economy, 1972, 80, 223-255.

Idler, E.L. and Y. Benyamini, "Self-rated health and mortality: A review of twenty-seven community studies," Journal of Health and Social Behavior, 1997, 38, 21-37.

Jürges, Hendrik, "True health vs. response styles: Exploring cross-country differences in self-reported health," Health Economics, 2007, 16 (2), 163-178.

, "Self-assessed health, reference levels, and mortality," Applied Economics, 2008, 40 (5), 569-582. 
_ _ and Kerstin Schneider, "What Can Go Wrong Will Go Wrong: Birthday Effects and Early Tracking in the German School System," Working Paper 2055, CESifo 2007.

, Mauricio Avendano, and Johan Mackenbach, "Are different measures of selfrated health comparable? An assessment in five European countries," European Journal of Epidemiology, 2008, 23 (12), 773-781.

Lindeboom, Maarten, Ana Llena Nozal, and Bas van der Klaauw, "Parental Education and Child Health: Evidence from a Schooling Reform," Journal of Health Economics, 2009, 28 (1), 109-131.

McCrary, Justin and Heather Royer, "The Effect of Female Education on Fertility and Infant Health: Evidence from School Entry Policies Using Exact Date of Birth," 2006. NBER working paper 12329.

Salm, Martin and Daniel Schunk, "The Role of Childhood Health for the Intergenerational Transmission of Human Capital: Evidence from Administrative Data," 2008. MEA Discussion Paper 164-08.

Schneider, Thorsten, "Social Inequality in Educational Participation in the Germany School System in a Longitudinal Perspective: Pathways into and out of the most Prestigious School Track," European Sociological Review, 2008, 24 (4), 511-525. 
Figure 1: The Gradient between log family income and subjective health for different age groups

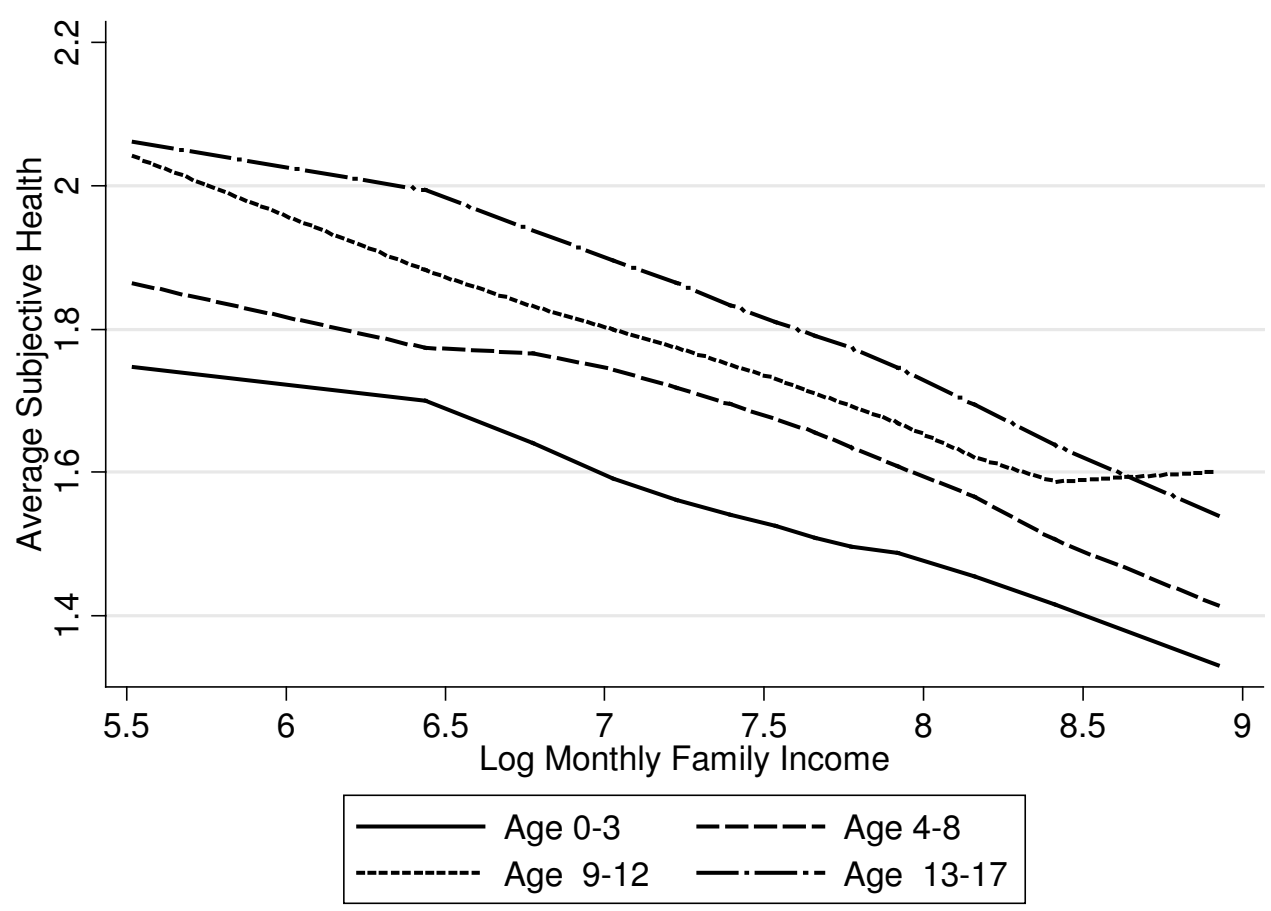


Table 1: Sample description

\begin{tabular}{|c|c|c|c|}
\hline Variable & Mean & Std. Dev. & $\mathbf{N}$ \\
\hline \multicolumn{4}{|l|}{ Child health } \\
\hline Subjective Health (Avg.) & 1.664 & 0.592 & 17414 \\
\hline Very good & 0.400 & 0.490 & 17414 \\
\hline Good & 0.537 & 0.499 & 17414 \\
\hline Fair or worse & 0.064 & 0.244 & 17414 \\
\hline Low birth weight & 0.062 & 0.241 & 16877 \\
\hline Hayfever & 0.098 & 0.297 & 17425 \\
\hline Neurodermatitis & 0.134 & 0.341 & 17270 \\
\hline Bronchitis & 0.126 & 0.332 & 17298 \\
\hline Asthma & 0.045 & 0.206 & 17393 \\
\hline Heart condition & 0.028 & 0.165 & 17404 \\
\hline Diabetes & 0.001 & 0.036 & 17406 \\
\hline Epilepsy & 0.009 & 0.096 & 16944 \\
\hline Glasses & 0.188 & 0.391 & 14784 \\
\hline Migraine & 0.022 & 0.147 & 17348 \\
\hline Scoliosis & 0.047 & 0.211 & 17313 \\
\hline Thyroid problems & 0.014 & 0.117 & 17315 \\
\hline Cramps & 0.034 & 0.181 & 17376 \\
\hline Anemia & 0.023 & 0.15 & 17308 \\
\hline Lung infection & 0.103 & 0.303 & 17338 \\
\hline High blood pressure & 0.059 & 0.235 & 14663 \\
\hline Low haemoglobin & 0.154 & 0.361 & 14075 \\
\hline Low ferritin & 0.128 & 0.334 & 13083 \\
\hline Obese & 0.061 & 0.24 & 14747 \\
\hline Age & 8.511 & 5.076 & 17641 \\
\hline Male & 0.491 & 0.5 & 17641 \\
\hline Academic track & 0.347 & 0.476 & 4747 \\
\hline Repeated Class & 0.127 & 0.333 & 9935 \\
\hline \multicolumn{4}{|l|}{ Family background } \\
\hline Ln family income & 7.679 & 0.566 & 16553 \\
\hline No migrant & 0.849 & 0.358 & 17641 \\
\hline Mother unemployed & 0.101 & 0.301 & 17641 \\
\hline Father unemployed & 0.082 & 0.275 & 17641 \\
\hline Private insurance & 0.192 & 0.394 & 17641 \\
\hline \multicolumn{4}{|l|}{ Mother's education } \\
\hline Basic school & 0.193 & 0.394 & 17641 \\
\hline Middle school & 0.429 & 0.495 & 17641 \\
\hline Grammar school & 0.137 & 0.344 & 17641 \\
\hline Some college+ & 0.156 & 0.363 & 17641 \\
\hline \multicolumn{4}{|l|}{ Father's education } \\
\hline Basic school & 0.249 & 0.432 & 17641 \\
\hline Middle school & 0.322 & 0.467 & 17641 \\
\hline Grammar school & 0.092 & 0.289 & 17641 \\
\hline Some college+ & 0.215 & 0.411 & 17641 \\
\hline
\end{tabular}


Table 2: Subjective Child Health and Log Family Income, Ordered Probit Regression Results

\begin{tabular}{lccccc} 
For ages & $0-17$ & $0-3$ & $4-8$ & $9-12$ & $13-17$ \\
\hline \hline \multirow{2}{*}{ Ln family income } & Baseline specification & & & \\
& $-0.262^{* * *}$ & $-0.240^{* * *}$ & $-0.259^{* * *}$ & $-0.229^{* * *}$ & $-0.313^{* * *}$ \\
& $(0.0198)$ & $(0.0466)$ & $(0.0379)$ & $(0.0400)$ & $(0.0376)$ \\
$N$ & 15807 & 3354 & 4498 & 3761 & 4194 \\
\hline \multirow{2}{*}{ Wn family income } & $-0.227^{* * *}$ & $-0.237^{* * *}$ & $-0.195^{* * *}$ & $-0.214^{* * *}$ & $-0.264^{* * *}$ \\
& $(0.0229)$ & $(0.0510)$ & $(0.0433)$ & $(0.0473)$ & $(0.0451)$ \\
Mother's education & & & & & \\
Intermediate School & -0.0511 & 0.00633 & $-0.112^{*}$ & -0.0860 & 0.00192 \\
& $(0.0279)$ & $(0.0649)$ & $(0.0535)$ & $(0.0557)$ & $(0.0530)$ \\
Grammar school & -0.0463 & 0.0264 & -0.105 & -0.0218 & -0.0757 \\
& $(0.0362)$ & $(0.0794)$ & $(0.0668)$ & $(0.0753)$ & $(0.0729)$ \\
College degree & -0.0533 & -0.0246 & $-0.185^{*}$ & 0.0276 & 0.00342 \\
& $(0.0380)$ & $(0.0861)$ & $(0.0728)$ & $(0.0766)$ & $(0.0731)$
\end{tabular}

Father's education

\begin{tabular}{lccccc} 
Intermediate School & $-0.0567^{*}$ & -0.111 & 0.0301 & -0.0471 & -0.0983 \\
& $(0.0273)$ & $(0.0613)$ & $(0.0518)$ & $(0.0558)$ & $(0.0524)$ \\
Grammar school & $-0.0972^{*}$ & -0.146 & -0.0297 & -0.0165 & $-0.188^{*}$ \\
& $(0.0382)$ & $(0.0804)$ & $(0.0697)$ & $(0.0799)$ & $(0.0808)$ \\
College degree & & & & & \\
& $-0.0772^{*}$ & -0.00415 & -0.0310 & -0.0848 & $-0.170^{* *}$ \\
& $(0.0329)$ & $(0.0740)$ & $(0.0630)$ & $(0.0667)$ & $(0.0621)$ \\
\hline
\end{tabular}

Standard errors in parentheses

${ }^{*} p<0.05,{ }^{* *} p<0.01,{ }^{* * *} p<0.001$

Control variables for the base line specification include a full set of age dummies (in years), sex of child, log of household size, parity of birth, dummy for being a twin, age of parents, dummies for family background and respondent, migrant status, dummies for East Germany and rural areas. The specification with additional controls include all of the above and dummies for parental education including a dummy for missing information (Basic education of 9 years is omitted category) and unemployment status. 


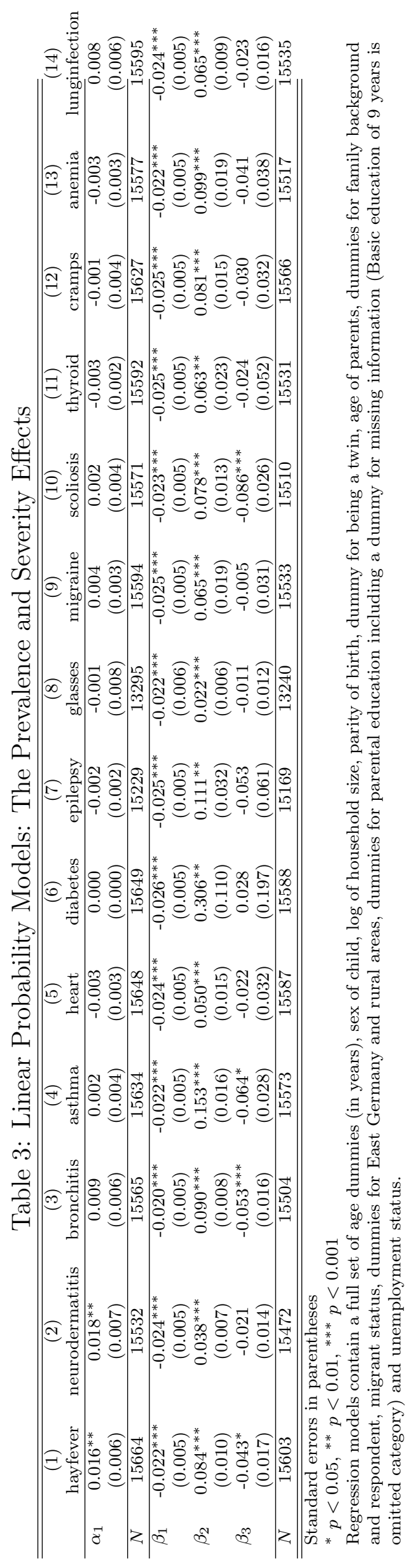


Table 4: The Long-term Impact of Low Birth Weight on Subjective Health. Ordered Probit Regression Results.

\begin{tabular}{|c|c|c|c|c|c|c|}
\hline & (1) & (2) & (3) & (4) & (5) & (6) \\
\hline Ln family income & $\begin{array}{c}-0.237^{* * *} \\
(0.023)\end{array}$ & $\begin{array}{c}-0.236^{* * *} \\
(0.023)\end{array}$ & $\begin{array}{c}-0.236^{* * *} \\
(0.023)\end{array}$ & $\begin{array}{c}-0.239^{* * *} \\
(0.024)\end{array}$ & $\begin{array}{c}-0.239^{* * *} \\
(0.024)\end{array}$ & $\begin{array}{c}-0.239^{* * *} \\
(0.024)\end{array}$ \\
\hline Low birth weight & & $\begin{array}{l}0.112^{* *} \\
(0.042)\end{array}$ & $\begin{array}{c}0.137 \\
(0.080)\end{array}$ & $\begin{array}{l}-0.247 \\
(0.561)\end{array}$ & $\begin{array}{c}0.137 \\
(0.080)\end{array}$ & $\begin{array}{l}-0.035 \\
(1.011)\end{array}$ \\
\hline $\begin{array}{l}\text { Low birth weight } \\
\times \text { age }\end{array}$ & & & $\begin{array}{l}-0.003 \\
(0.008)\end{array}$ & & $\begin{array}{l}-0.044 \\
(0.064)\end{array}$ & $\begin{array}{l}-0.029 \\
(0.115)\end{array}$ \\
\hline $\begin{array}{l}\text { Low birth weight } \\
\times \text { Ln family income }\end{array}$ & & & & $\begin{array}{c}0.047 \\
(0.073)\end{array}$ & & $\begin{array}{c}0.023 \\
(0.133)\end{array}$ \\
\hline $\begin{array}{l}\text { Low birth weight } \times \text { age } \\
\times \text { Ln family income }\end{array}$ & & & & & $\begin{array}{c}0.005 \\
(0.008)\end{array}$ & $\begin{array}{c}0.003 \\
(0.015)\end{array}$ \\
\hline$N$ & 15457 & 15457 & 15457 & 15457 & 15457 & 15457 \\
\hline
\end{tabular}

Standard errors in parentheses

${ }^{*} p<0.05,{ }^{* *} p<0.01,{ }^{* * *} p<0.001$

Control variables include a full set of age dummies (in years), sex of child, log of household size, parity of birth, a dummy for being a twin, age of parents, dummies for family background and respondent, a set of dummies for parental education (some college and more is omitted category) and employment status, migrant status, dummies for East Germany and rural areas. 
Table 5: Using Alternative Specifications for the Effect of Birth Weight. Ordered Probit Regressions of Subjective Health.

\begin{tabular}{lcccc}
\hline \hline & $(1)$ & $(2)$ & $(3)$ & $(4)$ \\
\hline Ln family income & $-0.236^{* * *}$ & $-0.236^{* * *}$ & $-0.236^{* * *}$ & $-0.229^{* * *}$ \\
& $(0.0233)$ & $(0.0234)$ & $(0.0234)$ & $(0.0256)$ \\
Low birth weight & $0.112^{* *}$ & & & \\
& $(0.0421)$ & & & \\
Birth weight & & $-0.0639^{* * *}$ & & \\
& & $(0.0179)$ & & \\
Log birth weight & & & $-0.204^{* * *}$ & \\
& & & $(0.0531)$ & \\
Fetal growth & & & & $-0.00226^{* *}$ \\
& & & & $(0.000843)$ \\
\hline$N$ & 15457 & 15457 & 15457 & 13531 \\
\hline \hline
\end{tabular}

Standard errors in parentheses

${ }^{*} p<0.05,{ }^{* *} p<0.01,{ }^{* * *} p<0.001$

Control variables include a full set of age dummies (in years), sex of child, log of household size, parity of birth, a dummy for being a twin, age of parents, dummies for family background and respondent, a set of dummies for parental education (some college and more is omitted category) and employment status, migrant status, dummies for East Germany and rural areas. 
Table 6: The Relationship between Parental Income and Objective Health Measures. Probit Models of High Blood Pressure, Obesity, Low Haemoglobin and Ferritin Content in Blood. OLS models for latent health index and count of chronic conditions

\begin{tabular}{lcccccc}
\hline \hline & $(1)$ & $(2)$ & $(3)$ & $(4)$ & $(5)$ & $(6)$ \\
& hbp & obese & lowhaemo & lowferritin & count & latenthealth \\
\hline Ln family income & 0.000859 & $-0.0106^{*}$ & -0.00205 & -0.00802 & $0.0614^{* *}$ & $0.0153^{*}$ \\
& $(0.00488)$ & $(0.00454)$ & $(0.00677)$ & $(0.00695)$ & $(0.0230)$ & $(0.00632)$ \\
Mother's education & & & & & \\
Intermediate School & -0.00645 & $-0.0194^{* * *}$ & 0.00581 & 0.0131 & 0.0417 & $0.0162^{*}$ \\
& $(0.00585)$ & $(0.00505)$ & $(0.00882)$ & $(0.00908)$ & $(0.0289)$ & $(0.00803)$ \\
Grammar school & -0.0132 & $-0.0237^{* * *}$ & 0.0172 & $0.0430^{* * *}$ & 0.0486 & 0.0140 \\
& $(0.00683)$ & $(0.00541)$ & $(0.0117)$ & $(0.0132)$ & $(0.0373)$ & $(0.0102)$ \\
College degree & -0.0124 & $-0.0290^{* * *}$ & 0.0181 & $0.0275^{*}$ & $0.122^{* *}$ & $0.0311^{* *}$ \\
& $(0.00716)$ & $(0.00559)$ & $(0.0124)$ & $(0.0132)$ & $(0.0403)$ & $(0.0112)$ \\
Father's education & & & & & & \\
Intermediate School & -0.0113 & -0.0100 & -0.00227 & 0.00608 & -0.0408 & -0.0100 \\
& $(0.00565)$ & $(0.00516)$ & $(0.00852)$ & $(0.00890)$ & $(0.0284)$ & $(0.00787)$ \\
Grammar school & -0.00155 & -0.00283 & -0.0128 & -0.00370 & 0.0176 & 0.00745 \\
& $(0.00812)$ & $(0.00752)$ & $(0.0108)$ & $(0.0118)$ & $(0.0398)$ & $(0.0112)$ \\
\hline College degree & -0.00680 & $-0.0203^{* *}$ & 0.00867 & 0.00485 & -0.0143 & -0.00222 \\
& $(0.00680)$ & $(0.00586)$ & $(0.0102)$ & $(0.0104)$ & $(0.0345)$ & $(0.00948)$ \\
\hline \hline
\end{tabular}

Standard errors in parentheses

${ }^{*} p<0.05,{ }^{* *} p<0.01,{ }^{* * *} p<0.001$

Probit models are estimated for the outcomes high blood pressure, obesity, low haemoglobin and low ferritin levels in blood. Marginal effects are reported. OLS models are estimated for the latent health index and the count of chronic conditions. Additional controls for the base line specification include age of child (quadratic for blood pressure, full set of age dummies for other outcomes), sex of child, $\log$ of household size, parity of birth, age of parents, dummies for family background and respondent, a set of dummies for parental education (some college and more is omitted category) and employment status, migrant status, dummies for East Germany and rural areas. 
Table 7: Robustness check: The Role of Private Insurance Status and Health Behavior. Ordered Probit Models.

\begin{tabular}{|c|c|c|c|}
\hline & $(1)$ & $(2)$ & $(3)$ \\
\hline Ln family income & $-0.234^{* * *}$ & $-0.224^{* * *}$ & $-0.217^{* * *}$ \\
\hline \multirow{3}{*}{ Private insurance } & $(0.0232)$ & $(0.0251)$ & \multirow[t]{3}{*}{$(0.0230)$} \\
\hline & 0.0452 & 0.451 & \\
\hline & $(0.0252)$ & $(0.364)$ & \\
\hline Private insurance $\times$ & & -0.0512 & \\
\hline Ln family income & & $(0.0459)$ & \\
\hline \multirow[t]{2}{*}{ Father smokes } & & & $0.0452^{*}$ \\
\hline & & & $(0.0214)$ \\
\hline \multirow[t]{2}{*}{ Mother smokes } & & & -0.00716 \\
\hline & & & $(0.0259)$ \\
\hline Parents smoke & & & 0.00794 \\
\hline in apartment & & & $(0.0252)$ \\
\hline \multirow{2}{*}{$\begin{array}{l}\text { Smoke during } \\
\text { pregnancy }\end{array}$} & & & $0.0597^{*}$ \\
\hline & & & $(0.0303)$ \\
\hline Drink during & & & -0.000839 \\
\hline pregnancy & & & $(0.0267)$ \\
\hline \multirow[t]{2}{*}{ Father overweight } & & & 0.0364 \\
\hline & & & $(0.0204)$ \\
\hline \multirow[t]{2}{*}{ Mother overweight } & & & $0.0788^{* * *}$ \\
\hline & & & $(0.0200)$ \\
\hline$N$ & 15807 & 15807 & 15807 \\
\hline
\end{tabular}

Standard errors in parentheses

${ }^{*} p<0.05,{ }^{* *} p<0.01,{ }^{* * *} p<0.001$

Additional controls for the base line specification include a full set of age dummies (in years), sex of child, log of household size, parity of birth, a dummy for being a twin, age of parents, dummies for family background and respondent, a set of dummies for parental education (some college and more is omitted category) and employment status, migrant status, dummies for East Germany and rural areas. 


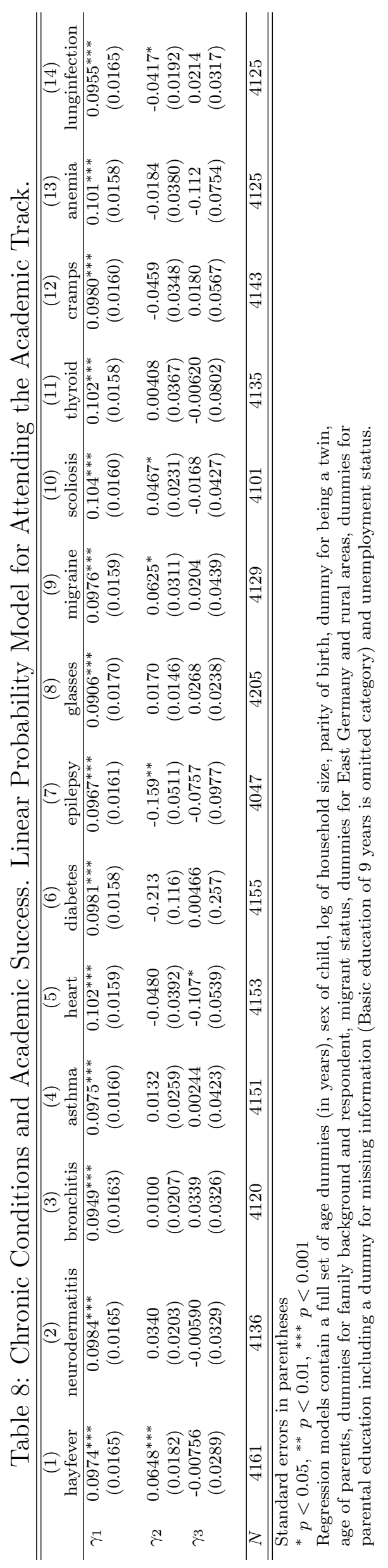


Table 9: Long-term Impact of Low Birth Weight on Educational Success. Linear Probability Models of Attending the Academic Track

\begin{tabular}{|c|c|c|c|c|}
\hline & $(1)$ & $(2)$ & $(3)$ & (4) \\
\hline Ln family incomed & $\begin{array}{c}0.106^{* * *} \\
(0.016)\end{array}$ & $\begin{array}{c}0.105^{* * *} \\
(0.016)\end{array}$ & $\begin{array}{c}0.106^{* * *} \\
(0.016)\end{array}$ & $\begin{array}{c}0.105^{* * *} \\
(0.016)\end{array}$ \\
\hline $\begin{array}{l}\text { Mother's education } \\
\text { Intermediate School }\end{array}$ & $\begin{array}{c}0.087^{* * *} \\
(0.019)\end{array}$ & $\begin{array}{c}0.085^{* * *} \\
(0.019)\end{array}$ & $\begin{array}{c}0.085^{* * *} \\
(0.019)\end{array}$ & $\begin{array}{c}0.085^{* * *} \\
(0.019)\end{array}$ \\
\hline Grammar school & $\begin{array}{c}0.233^{* * *} \\
(0.028)\end{array}$ & $\begin{array}{l}0.231^{* * *} \\
(0.028)\end{array}$ & $\begin{array}{c}0.231^{* * *} \\
(0.028)\end{array}$ & $\begin{array}{c}0.231^{* * *} \\
(0.028)\end{array}$ \\
\hline College degree & $\begin{array}{c}0.284^{* * *} \\
(0.028)\end{array}$ & $\begin{array}{c}0.281^{* * *} \\
(0.028)\end{array}$ & $\begin{array}{c}0.281^{* * *} \\
(0.028)\end{array}$ & $\begin{array}{c}0.281^{* * *} \\
(0.028)\end{array}$ \\
\hline $\begin{array}{l}\text { Father's education } \\
\text { Intermediate School }\end{array}$ & $\begin{array}{c}0.079^{* * *} \\
(0.020)\end{array}$ & $\begin{array}{l}0.079^{* * *} \\
(0.020)\end{array}$ & $\begin{array}{c}0.079^{* * *} \\
(0.020)\end{array}$ & $\begin{array}{c}0.079^{* * *} \\
(0.020)\end{array}$ \\
\hline Grammar school & $\begin{array}{c}0.137^{* * *} \\
(0.031)\end{array}$ & $\begin{array}{c}0.137^{* * *} \\
(0.031)\end{array}$ & $\begin{array}{c}0.137^{* * *} \\
(0.031)\end{array}$ & $\begin{array}{c}0.137^{* * *} \\
(0.031)\end{array}$ \\
\hline College degree & $\begin{array}{c}0.260^{* * *} \\
(0.025)\end{array}$ & $\begin{array}{c}0.261^{* * *} \\
(0.025)\end{array}$ & $\begin{array}{c}0.261^{* * *} \\
(0.025)\end{array}$ & $\begin{array}{c}0.261^{* * *} \\
(0.025)\end{array}$ \\
\hline Low birth weight & & $\begin{array}{c}-0.098^{* * *} \\
(0.026)\end{array}$ & $\begin{array}{c}-0.098^{* * *} \\
(0.026)\end{array}$ & $\begin{array}{c}-0.096^{* *} \\
(0.032)\end{array}$ \\
\hline $\begin{array}{l}\text { Low birth weight } \times \\
\text { Ln family income }\end{array}$ & & & $\begin{array}{l}-0.028 \\
(0.045)\end{array}$ & \\
\hline $\begin{array}{l}\text { Low birth weight } \times \\
\text { high income }\end{array}$ & & & & $\begin{array}{l}-0.003 \\
(0.048)\end{array}$ \\
\hline$N$ & 4045 & 4045 & 4045 & 4045 \\
\hline
\end{tabular}

Standard errors in parentheses

${ }^{*} p<0.05,{ }^{* *} p<0.01,{ }^{* * *} p<0.001$

Regression models contain a full set of age dummies (in years), sex of child, log of household size, parity of birth, dummy for being a twin, age of parents, dummies for family background and respondent, migrant status, dummies for East Germany and rural areas, dummies for parental education including a dummy for missing information (Basic education of 9 years is omitted category) and unemployment status. 
Table 10: Robustness Check: Different Definition of Educational Success. Linear Probability Models of Grade Retention

\begin{tabular}{|c|c|c|c|c|}
\hline & (1) & $(2)$ & $(3)$ & $(4)$ \\
\hline Ln family income & $\begin{array}{c}-0.036^{* * *} \\
(0.009)\end{array}$ & $\begin{array}{c}-0.036^{* * *} \\
(0.009)\end{array}$ & $\begin{array}{c}-0.035^{* * *} \\
(0.009)\end{array}$ & $\begin{array}{c}-0.035^{* * *} \\
(0.009)\end{array}$ \\
\hline Mother's education & & & & \\
\hline Intermediate School & $\begin{array}{l}-0.021 \\
(0.011)\end{array}$ & $\begin{array}{c}-0.021 \\
(0.011)\end{array}$ & $\begin{array}{l}-0.021 \\
(0.011)\end{array}$ & $\begin{array}{l}-0.021 \\
(0.011)\end{array}$ \\
\hline Grammar school & $\begin{array}{r}-0.027^{*} \\
(0.013)\end{array}$ & $\begin{array}{c}-0.027^{*} \\
(0.013)\end{array}$ & $\begin{array}{r}-0.027^{*} \\
(0.013)\end{array}$ & $\begin{array}{c}-0.027^{*} \\
(0.013)\end{array}$ \\
\hline College degree & $\begin{array}{c}-0.057^{* * *} \\
(0.013)\end{array}$ & $\begin{array}{c}-0.057^{* * *} \\
(0.013)\end{array}$ & $\begin{array}{c}-0.057^{* * *} \\
(0.013)\end{array}$ & $\begin{array}{c}-0.057^{* * *} \\
(0.013)\end{array}$ \\
\hline $\begin{array}{l}\text { Father's education } \\
\text { Intermediate School }\end{array}$ & $\begin{array}{r}-0.022^{*} \\
(0.011)\end{array}$ & $\begin{array}{l}-0.021^{*} \\
(0.011)\end{array}$ & $\begin{array}{l}-0.021^{*} \\
(0.011)\end{array}$ & $\begin{array}{l}-0.021^{*} \\
(0.011)\end{array}$ \\
\hline Grammar school & $\begin{array}{l}-0.017 \\
(0.014)\end{array}$ & $\begin{array}{l}-0.017 \\
(0.014)\end{array}$ & $\begin{array}{l}-0.017 \\
(0.014)\end{array}$ & $\begin{array}{l}-0.018 \\
(0.014)\end{array}$ \\
\hline College degree & $\begin{array}{r}-0.029^{*} \\
(0.011)\end{array}$ & $\begin{array}{l}-0.029^{*} \\
(0.011)\end{array}$ & $\begin{array}{l}-0.029^{*} \\
(0.011)\end{array}$ & $\begin{array}{l}-0.029^{*} \\
(0.011)\end{array}$ \\
\hline Low birth weight & & $\begin{array}{c}0.029 \\
(0.016)\end{array}$ & $\begin{array}{c}0.029 \\
(0.016)\end{array}$ & $\begin{array}{c}0.043 \\
(0.026)\end{array}$ \\
\hline $\begin{array}{l}\text { Low birth weight } \times \\
\text { Ln family income }\end{array}$ & & & $\begin{array}{l}-0.009 \\
(0.029)\end{array}$ & \\
\hline $\begin{array}{l}\text { Low birth weight } \times \\
\text { high income }\end{array}$ & & & & $\begin{array}{l}-0.028 \\
(0.031)\end{array}$ \\
\hline$N$ & 8663 & 8663 & 8663 & 8663 \\
\hline
\end{tabular}

Standard errors in parentheses

${ }^{*} p<0.05,{ }^{* *} p<0.01,{ }^{* * *} p<0.001$

Regression models contain a full set of age dummies (in years), sex of child, log of household size, parity of birth, dummy for being a twin, age of parents, dummies for family background and respondent, migrant status, dummies for East Germany and rural areas, dummies for parental education including a dummy for missing information (Basic education of 9 years is omitted category) and unemployment status. 


\section{Discussion Paper Series}

Mannheim Research Institute for the Economics of Aging, Universität Mannheim

To order copies, please direct your request to the author of the title in question.

\begin{tabular}{|c|c|c|c|}
\hline Nr. & Autoren & Titel & Jahr \\
\hline $162-08$ & $\begin{array}{l}\text { Axel Börsch-Supan, } \\
\text { Karsten Hank, } \\
\text { Hendrik Jürges, } \\
\text { Mathis Schröder } \\
\end{array}$ & $\begin{array}{l}\text { Longitudinal Data Collection in Continental } \\
\text { Europe: Experiences from the Survey of Health, } \\
\text { Ageing and Retirement in (SHARE) }\end{array}$ & 08 \\
\hline $163-08$ & Martin Salm & Job loss does not cause ill health & 08 \\
\hline 164-08 & $\begin{array}{l}\text { Martin Salm, Daniel } \\
\text { Schunk }\end{array}$ & $\begin{array}{l}\text { The role of childhood health for the inter- } \\
\text { generational transmission of human capital: } \\
\text { Evidence from administrative data }\end{array}$ & 08 \\
\hline $165-08$ & Christina Benita Wilke & $\begin{array}{l}\text { On the feasibility of notional defined contribution } \\
\text { systems: The German case }\end{array}$ & 08 \\
\hline $166-08$ & $\begin{array}{l}\text { Alexander Ludwig } \\
\text { Michael Reiter }\end{array}$ & $\begin{array}{l}\text { Sharing Demographic Risk - Who is Afraid of } \\
\text { the Baby Bust? }\end{array}$ & 08 \\
\hline $167-08$ & $\begin{array}{l}\text { Jürgen Maurer } \\
\text { André Meier }\end{array}$ & $\begin{array}{l}\text { Smooth it Like the "Joneses?" Estimating Peer- } \\
\text { Group Effects in Intertemporal Consumption } \\
\text { Choice }\end{array}$ & 08 \\
\hline 168-08 & $\begin{array}{l}\text { Melanie Lührmann } \\
\text { Jürgen Masurer }\end{array}$ & $\begin{array}{l}\text { Who wears the trousers? A semiparametric } \\
\text { analysis of decision power in couples }\end{array}$ & 08 \\
\hline $170-08$ & Jürgen Maurer & $\begin{array}{l}\text { Who has a clue to preventing the flu? } \\
\text { Unravelling supply and demand effects on the } \\
\text { take-up of influenza vaccinations }\end{array}$ & 08 \\
\hline $171-08$ & $\begin{array}{l}\text { Johannes Binswanger } \\
\text { Daniel Schunk }\end{array}$ & $\begin{array}{l}\text { What Is an Adequate Standard of Living } \\
\text { during Retirement? }\end{array}$ & 08 \\
\hline $172-08$ & $\begin{array}{l}\text { Mathis Schröder } \\
\text { Axel Börsch-Supan }\end{array}$ & Retrospective Data Collection in Europe & 08 \\
\hline $173-09$ & Michael Ziegelmeyer & $\begin{array}{l}\text { Documentation of the logical imputation using } \\
\text { the panel structure of the 2003-2008 German } \\
\text { SAVE Survey }\end{array}$ & 09 \\
\hline $174-09$ & $\begin{array}{l}\text { Axel Börsch-Supan, } \\
\text { Tabea Bucher-Koenen, } \\
\text { Martin Gasche und } \\
\text { Christina Benita Wilke }\end{array}$ & $\begin{array}{l}\text { Ein einheitliches Rentensystem für } \\
\text { Ost- und Westdeutschland - } \\
\text { Simulationsrechnungen zum Reformvorschlag } \\
\text { des Sachverständigenrates }\end{array}$ & 09 \\
\hline $175-09$ & $\begin{array}{l}\text { Steffen Reinhold, } \\
\text { Hendrik Jürges }\end{array}$ & Parental Income and Child Health in Germany & 09 \\
\hline
\end{tabular}

